\title{
The Use of Remote Sensing Data to Improve the Efficiency of Pastoral Sheep
}

\author{
Vladimir Trukhachev, Serhii Oliinyk, Tatiana Lesnyak, Vitaly Morozov, Maria Ponomareva
}

\begin{abstract}
: in the study of agricultural land, the priority is the use of remote monitoring techniques using unmanned aerial vehicles, technological portable devices. Obtaining materials by remote methods will expand the possibilities of introducing grazing livestock, increase the yield and thereby improve the efficiency of production indicators. The article considers the issues of assessing the nutritional value of pasture fodder, in particular, the amino acid composition in combination with the vegetation index in the conditions of pasture livestock raising in the Stavropol Territory. Productive qualities of replacement young animals directly depend on the quality of feed. Monitoring the amino acid composition of feeds allows you to optimize the technology of growing sheep, taking into account their productivity direction. The combination of remote methods for assessing the vegetation index and the in-depth composition of the nutritional value of feeds makes it possible to optimize the production schedule for the use of pasture plots by various sex and age groups of animals and increase the average daily gain in live weight of young fattening groups by $8-10 \%$. It has been shown that the introduction of top-dressing with roughage in especially dry periods contributes to preserve of animal growth energy when changing grazing areas. Remote assessment of pasture vegetation was carried out using a special camera to calculate the NDVI (Normalized Difference Vegetation Index), which was installed on an unmanned aerial vehicle. At the same time, the dynamics of the NDVI using a portable manual nitrogen sensor was studied in the same pasture plots. The obtained results of monitoring of the vegetative index on pasture plots were compared with the results of chemical analysis of plant feed. Information on the availability of gross amount of plant biomass in the fields was used for priority selection of a specific site for grazing animals and optimizing the use of agricultural territories. It was proven that the parameters of the NDVI for the pasture keeping of young sheep should not be lower than 0.4. The development and implementation of innovative methods of aerospace monitoring makes it possible to increase the efficiency of land use and increase the efficiency of grazing.
\end{abstract}

Keywords: amino acid composition of feed, nutritional value, pasture feed, sheep, vegetation index

Revised Manuscript Received on April 25, 2020.

* Correspondence Author

Vladimir Trukhachev*, Stavropol State Agrarian University, Stavropol, Russia. Email: soliynik60@gmail.com

Serhii Oliinyk*, Stavropol State Agrarian University, Stavropol, Russia. Email: soliynik60@gmail.com

Tatiana Lesnyak, Stavropol State Agrarian University, Stavropol, Russia.Email: soliynik60@gmail.com

Vitaly Morozov, Stavropol State Agrarian University, Stavropol,

Russia, Email: soliynik60@gmail.com

Maria Ponomareva, Stavropol State Agrarian University, Stavropol, Russia. Email: soliynik60@gmail.com

(c) The Authors. Published by Blue Eyes Intelligence Engineering and Sciences Publication (BEIESP). This is an open access article under the CC BY-NC-ND license (http://creativecommons.org/licenses/by-nc-nd/4.0/)

\section{INTRODUCTION}

A promising direction for increasing the efficiency of production forecasting in the field of pasture livestock raising is the use of modern innovative digital technologies, an example of which are geographic information systems for the global positioning of agricultural land. In accordance with the Concept for the Development of Agriculture in Russia, for the effective management of the country's agro-industrial complex, it is necessary to carry out state monitoring of such lands, regardless of the form of ownership and the form of introduction of agricultural activity on them [3]. The transition to a new type of farming is taking place in many developed countries, the largest part of the land market covered by remote monitoring (about 53\%) is currently located in North America, which is largely due to a high degree of interest in "smart" innovations on the part of farmers [4]. Intelligent technologies are most actively introduced into small-scale field farming and pastoral livestock [2]. In a modern livestock farm, not only ground-based unmanned vehicles can be used, but also unmanned aerial vehicles (UAVs) equipped with cameras and highly sensitive sensors. UAVs are able to examine agricultural areas of impressive size in a few hours of operation, and the information collected using various technological equipment (cameras, thermal imagers and sensors) allows the farmer to create electronic field maps in 3D format, calculate the Normalized Difference Vegetation Index (NDVI) ) to effectively fertilize plant crops, conduct an inventory of work performed, protect farmland. Currently, there are startups on the international and Russian markets that offer to plant plants using specialized drones that shoot seeds in a capsule in the soil, which is of particular interest to increase the fertility of natural pastures [5]. In Russia, among the most active participants in the UAV application market, there are a number of companies that provide a wide range of services for agriculture. For example, NPP New Technologies of Telecommunications (St. Petersburg) and Geoscan provide agricultural producers with assistance in creating cartographic fields and calculating NDVI and other indices, in the accompaniment and monitoring of agrotechnical measures [6]. Earth remote sensing (ERS) technologies provide for aerospace photography of agricultural land, as well as grazing land [1]. Modern aerial photography equipment (digital cameras) is usually divided into two categories: metric and nonmetric; when using an unmanned aerial vehicle, cameras with a weight of 1-32 kg should be used [8].

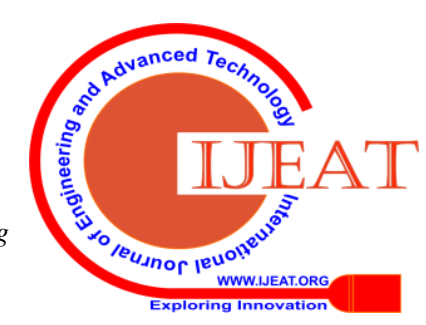


Remote monitoring data have recently been successfully used in the Stavropol Territory [7], which is known for its well-developed pasture sheep farming.

Ensuring proper feeding of sheep is an important prerequisite for the successful realization of the genetically determined potential of animal development in accordance with the breed's capabilities. At the same time, one of the main problems in ensuring biologically proper nutrition of sheep is the assessment of the properties of feed protein and the composition of its amino acids. Given that the Jalgin merino sheep breed has a double meat-wool productivity direction, the presence of essential and sulfur-containing amino acids cysteine, cystine, methionine - is of particular importance for growing, since their presence in feed contributes to the growth of wool. For this reason, unlike other animal species, sheep are much more sensitive to the species composition and quality of green feed and roughage. It is known that feeding different age and sex groups of sheep with millet straw leads to a deterioration in the quality of wool. Similarly, the effect of hay from large-stemmed acidic meadow cereals and hay containing burdock plants is shown. Especially the lack of amino acids and minerals in the feeding diet is manifested in the winter, in practice, this can lead to a mass death of young animals.

Thus, modern approaches to the development of an innovative system of pasture livestock husbandry should include monitoring of the nutritional value and amino acid composition of feed in combination with the use of digital aerospace technologies and telemetry.

\section{MATERIALS AND RESEARCH METHODS}

Pasture forages for research were selected during the period of the main vegetation of plants (June-July) and were studied by standard methods. The chemical composition of the feed (crude protein, crude fiber, crude fat, crude ash, calcium, phosphorus, amino acid composition) and moisture were determined using equipment from INGOS (Czech Republic), FIBRETHERM (Germany), VELP SCIENTIFICA (Italy) in the STC "Feed and metabolism "(accreditation certificate No.ROSS RU.0001.21PU12 dated 10.28.2014).

The free forms of amino acids in feed (total cystine and cysteine; methionine; lysine; threonine; alanine; aspartic acid; glutamic acid; glycine; histidine; isoleucine; leucine; phenylalanine; proline; serine; tyrosine; valine) were determined by extraction with diluted hydrochloric acid. Nitrogen macromolecules extracted with amino acids were precipitated with sulfosalicylic acid and filtered. The acidity of the filter medium was adjusted to a value of $2.20 \mathrm{pH}$. Amino acids were separated by ion exchange chromatography, a reaction was carried out with ninhydrin, and their concentration was determined by photometric detection at a wavelength of $570 \mathrm{~nm}$. The determination of the total content (free and bound forms in total) of the individual amino acids was carried out by the method depending on the determined individual amino acids. Before hydrolysis, cystine (cysteine) and methionine were oxidized to cysteic acid and methionine sulfone, respectively. Tyrosine was determined in hydrolysates of unoxidized samples. All other amino acids mentioned above were determined in both oxidized and non-oxidized samples. The oxidation was carried out at a temperature of $0^{\circ} \mathrm{C}$ with a mixture of performic acid with phenol. Excess oxidizing agent is decomposed by sodium disulfide. Oxidized or non-oxidized samples were hydrolyzed with hydrochloric acid at a molar concentration of $6 \mathrm{~mol} / \mathrm{dm}$ for 23 hours. The acidity of the hydrolyzate medium was adjusted to $2.20 \mathrm{pH}$. Amino acids were separated by ion exchange chromatography, derivatized with ninhydrin and detected at a wavelength of $570 \mathrm{~nm}$ (440 nm for proline) [7].

Groups of animals for research were formed based on analogue pairs from young animals of the Jalgin merino sheep fattening group. The number of young sheep for fattening in each group was 100 animals; the age of the animals was 6 months. The control period for growing experimental animals was 60 days. The live weight of animals was determined by weighing on livestock scales with an error of $\pm 0.10 \mathrm{~kg}$.

In our studies, groups of sheep grazed on pastures, the botanical composition of which consisted of leguminous and cereal plants (25:75\%): onobrychis, medicago, festuca pratensis, lolium perenne. Determination of live weight of experimental young animals was carried out by standard zootechnical method by weighing. The study of pasture ecosystems was carried out using an AS-32-10 unmanned aerial vehicle and a DJI 900 hexacopter, a Canon EOS 650D camera and normalized difference vegetation index (NDVI) calculation software.

We used a modified camera with a red Wratten 25A filter, which allows you to register two independent image channels on a single image - visible red (600 - $700 \mathrm{~nm})$ or blue and near infrared (700-950 nm). The NDVI was calculated as the ratio of the difference between the brightness of pixels in the IR and red (blue) channels to their total

NDVI was calculated using the following formula:

$$
N D V I=\frac{N I R-R e d(B l u e)}{N I R+R e d(B l u e)}
$$

where NIR is the reflection in the near infrared region of the spectrum; Red (Blue) - reflection in the red (blue) region of the spectrum.

To obtain averaged NDVI values taking into account areal coefficients, the calculation method using the regression equation was used.

\section{RESEARCH RESULTS AND DISCUSSION}

Remote sensing and chemical analysis of pasture feeds made it possible to establish that the value of the vegetation index of pasture plants in plots where experimental groups of animals were grazed ranged from 0.41 to 0.61 . Depending on the value of the NDVI index, the nutritional value of pasture feeds was at a different level (Table 1).

Table- I: Nutritional value of pasture feed, \%

\begin{tabular}{l|c|c|}
\hline \multicolumn{1}{|c|}{ Indicator } & NDVI 0.41 & NDVI 0.61 \\
\hline Crude protein & 2.9 & 4.55 \\
\hline Total humidity & 31.49 & 42.97 \\
\hline Crude fiber & 25.78 & 18.13 \\
\hline Crude fat & 1.39 & 1.75 \\
\hline
\end{tabular}




\begin{tabular}{|l|c|c|}
\hline \multicolumn{1}{|c|}{ Indicator } & NDVI 0.41 & NDVI 0.61 \\
\hline Raw ash & 3.36 & 3.84 \\
\hline Calcium & 0.39 & 0.41 \\
\hline Phosphorus & 0.23 & 0.20 \\
\hline
\end{tabular}

At the same time, in the group of pasture feeds with the NDVI index value of 0.61 , the indicators of crude protein, total moisture, crude fat, crude ash and calcium are on average 5.0-57.0\% higher than those of the group of pasture feeds with an index value of NDVI 0.41. In the opposite relationship are indicators of the vegetation index and the content of crude fiber and phosphorus.

The results of studying the amino acid composition of pasture feeds in combination with the vegetation index for raising sheep of the Jalgin merino breed in the conditions of the steppe regions of the Stavropol Territory are presented in Figure 1.

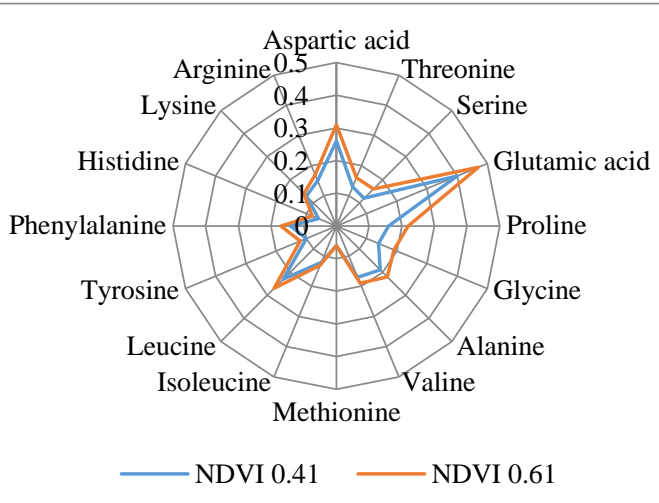

Fig. 1. Amino acid composition of pasture feed, $\%$

According to the data obtained in group II with a higher vegetation index of grazing feed, the content of non-essential and essential amino acids was on average 7.7-47.6\% higher than in group I. Thus, the content of Aspartic acid (Asp) in the second group (NDVI is 0.61 ), was $47.6 \%$ higher than in the first group (NDVI is 0.41 ), similarly for other amino acids, Threonine (Thr) - 23.1\%, Serine (Ser) - by 33.3\%, Glutamic acid (Glu) - by 17.5\%, Proline (Pro) - by 37.5\%, Glycine (Gly) - by 35.7\%, Alanine (Ala) - by $24.4 \%$, Valin (Val) - by $11.8 \%$, Isoleucine (Lie) - by $8.3 \%$, Leucine (Leu) by $17.4 \%$, Tyrosine (Tyr) - by $20.0 \%$, Phenylalanine (Phe) 21.4\%, Histidine (His) - 33.3\%, Lysine (Lys) - 7.7\%, Arginine (Arg) - 13, 3\%

Figure 2 shows the dynamics of changes in the vegetation index for the period from 02/02/2018 to $02 / 11 / 2018$.

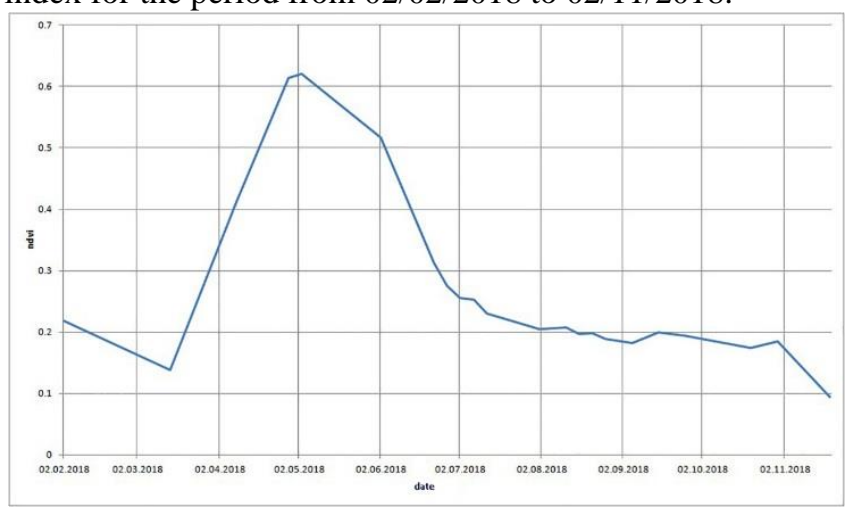

Fig. 2. Averaged NDVI values taking into account areal coefficients

The data was calculated using the regression equation: $y=1 E-13 x 6-9 E-11 x 5+3 E-08 x 4-3 E-06 x 3-6 E-05 x 2+$ $0.0174 \mathrm{x}-0.002$

where $\mathrm{y}$ is NDVI, $\mathrm{x}$ - days from the start date (February 02, 2018).

Evaluation of the effectiveness of growing sheep in experimental groups allowed us to determine the optimal range of dynamics of the NDVI index, which is 0.41-0.61.

The productive qualities of replacement young animals directly depend on the quality of the feed. The live weight of the experimental animals at the beginning of the experiment was at the same level and amounted to 33.35-33.25 kg (Table 2).

Table- II: Productive quality of replacement young animals 6-8 months of age

\begin{tabular}{|l|c|c|c|}
\hline \multicolumn{2}{|c|}{ Indicator } & \multicolumn{2}{c|}{ Группа } \\
\cline { 3 - 4 } & I & II \\
\hline $\begin{array}{l}\text { The average live weight at the } \\
\text { beginning of the experiment, } \mathrm{kg}\end{array}$ & $\mathrm{M} \pm \mathrm{m}$ & $33.35 \pm 1.23$ & $33.25 \pm 1.12$ \\
\hline $\begin{array}{l}\text { The average live weight at the end } \\
\text { of the experiment, kg }\end{array}$ & $\mathrm{M} \pm \mathrm{m}$ & $39.03 \pm 1.57$ & $39.56 \pm 1.48$ \\
\hline $\begin{array}{l}\text { The average daily gain in live } \\
\text { weight, g }\end{array}$ & $\mathrm{M} \pm \mathrm{m}$ & $94.63 \pm 1.09 *$ & $105.10 \pm 1.05^{*}$ \\
\hline
\end{tabular}

The combination of remote methods for assessing the vegetation index and the in-depth composition of the nutritional value of feed, as well as the addition of roughage in particularly dry periods, contributed to a $10 \%$ increase in the average daily gain in live weight of young animals during rearing in group II.

Replacement young sheep should preferably be grazed on pastures with vegetation index higher than 0.60. Moreover, the vegetative index NDVI adequately reflects the accumulation of nutrients in plants, which coincides with the studies of Prasad S. [9]. In our opinion, the measurement range of the vegetation index 500-550 nm accurately reflects the change in the nutritional value of pasture plants.

It is advisable to select the optimal pasture area to reduce labor costs and conduct remote assessment of the condition of pasture feeds using unmanned aerial vehicles, such as an aircraft type AC-32-10 or a DJI 900 hexacopter, which are equipped with a Canon M10 camera and software for calculating the vegetation index (NDVI).

\section{CONCLUSIONS}

1. It is advisable to use remote methods for determining the vegetation index using unmanned aerial vehicles, such as an aircraft type AC-32-10 or a DJI 900 hexacopter, which are equipped with a Canon M10 camera and software for calculating the vegetation index (NDVI) during rearing replacement Jalgin merino sheep.

2. When choosing a pasture site for growing young stock of sheep of the Jalgin merino breed, it is desirable to use areas with a vegetation index of NDVI of 0.4-0.6, which will allow animals to realize a genetically determined development potential of $105 \mathrm{~g}$ of average daily gain in live weight.

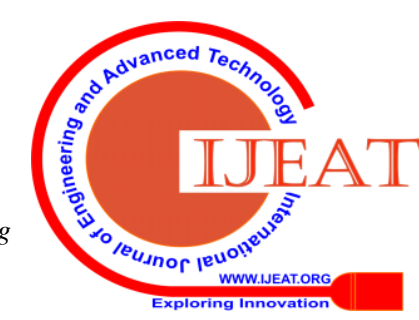




\section{ACKNOWLEDGMENT}

The work was supported by the Ministry of Education and Science of the Russian Federation; electronic budget agreement number 075-02-208-920; internal agreement number 14.613.21.0081; 14.613.21.0081 and the Russian Ministry of Education dated November 22, 2017; unique work identifier:

RFMEFI61317X0081 R\&D registration number AAAAA18-118040390089-9.

\section{REFERENCES}

1. Abrosimov A.V. Prospects of application of remote sensing data from space to improve the efficiency of agriculture in Russia // Geomatics. 2009. No. 4. P. 46-49.

2. Geokurs [Electronic resource] / parallel driving Systems. - Access mode: http://agrogps.kz/, free. The title. from the screen.(date of application 09.10.2018 G.)

3. Agro-satellite information portal [Electronic resource] / will investments Save agriculture? http://www.agro- sputnik.ru/index.php/news/184-spasut-li-innovacii . The title. from the screen. (date of application 09.10.2018 G.)

4. How space technology can help agriculture [electronic resource www.sovzond.ru] (accessed 09.10.2018 G.)

5. Kantemirov I. the possibilities of satellite radar monitoring for solving problems of agriculture Geomatics. 2011. No. 2. P. 85-89.

6. Karaev V. V. Drones in agriculture / / Collection: scientific works of students of the mountain state agrarian University "Student science-agro-industrial complex" in 2 parts. Vladikavkaz, 2016. P. 22-26.

7. Kormschikova M. Federal "ATLAS of agricultural lands" // Geomatics. 2013. No. 1. P. 39-47.

8. Manylov I. V. evaluation of the efficiency of aerial photography equipment in the implementation of agricultural land monitoring tasks / / Information and control systems. - 2012. - № 2. - P. 13-17.

9. Prasad S. Thenkabail, Ronald B. Smith and Eddy De Pauw. Hyperspectral vegetation indices and their relationships with agricultural crop characteristics. // Remote sensing environmental, pp. 158-182.

\section{AUTHORS PROFILE}

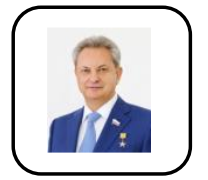

Vladimir Trukhachev doctor of agricultural sciences, doctor of economics, professor, department of animal feeding and general biology, Academician of the Russian academy of sciences, Stavropol State Agrarian University.

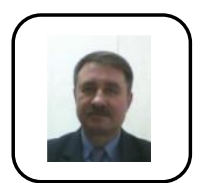

Serhii Oliinyk doctor of agricultural sciences, professor, department of special zootechnics, animal breeding and breeding, Stavropol State Agrarian University.

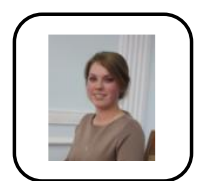

Tatiana Lesnyak candidate of agricultural sciences, associate professor, department of animal feeding and general biology, Stavropol State Agrarian University.

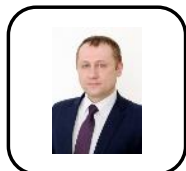

Vitaly Morozov doctor of veterinary sciences, associate professor, department of epizootology and microbiology, Stavropol State Agrarian University.

Maria Ponomareva candidate of veterinary sciences, associate professor, department of animal feeding and general biology, Stavropol State Agrarian University. 